\title{
Breathing Rhythm-generation in the Adult Lamprey, Entosphenus japonicus
}

\author{
Ryoji KAWASAKI \\ The College of Bio-Medical Technology of Niigata University, \\ Asahimachi, Niigata City, Niigata, 951 Japan
}

\begin{abstract}
The breathing rhythm-generation mechanism was studied throughout the entire body of the adult lamperey, Entosphenus japonicus, with the body fixed by a specially-designed holder.

2. After brain-stem transection, the rostral part (pontine area) and the caudal part of the medulla (Fig. 2) were found not essential for the generation of respiratory rhythm: the location of the medullary respiratory rhythm-generator was in the district limited by two crosssection lines (Fig. 2).

3. Complete division of the brain-stem into two halves by midline section revealed that both of the two symmetrical halves could function independently with their own frequencies for $2 \mathrm{hr}$ or longer.

4. Respiratory burst discharges were recorded from the isolated medial part of the medulla, preceded by a so-called diastolic slow depolarization. The forms of these neural activities resemble those reported in pacemaker cells in some crustacean heart ganglion. No periodic discharges correlating exclusively to the relaxation and/or resting period of branchial muscle were observed.

5. The reciprocal inhibition model was not necessarily considered a prerequisite for medullary respiratory rhythm-generation in the lamprey.
\end{abstract}

As members of the agnatha class, the lampreys possess a respiratory apparatus which consists of a branchial basket of elastic cartilage containing several pairs of vascularized gill sacs. The branchial muscles are involved in the contraction of the branchial basket for exhalation of water from the gill sacs. Inhalation of water is accomplished by elastic recoil of the branchial basket, when the branchial muscle is relaxed (RANDALL, 1972; ROBERTS, 1950).

Most of the branchial muscles in lampreys are innervated by the IXth and Xth cranial nerves (TretJakofF, 1927; Cords, 1929; Addens, 1933; LindSTROM, 1949). Motoneurons to the branchial muscles are located primarily in the ipsilateral motor nucleus of the vagus and exhibit periodic bursts of excitatory

Received for pubication January 25, 1979

川崎了二 
synaptic potential (RovaInen, 1974; Honma, 1975). RovaINEN (1974) revealed by sectioning the brain that the medulla is essential for breathing and removal of the fore- and midbrain at the isthmus had no effect on respiration. However, no details were given as to the mechanism which sends respiratory discharges to the branchial motoneurons (RovaINEN, 1977).

After considering the reciprocal inhibition model proposed for breathing rhythm-generation in mammals, it would be interesting to know whether the model is applicable to the case of lampreys which possess only a synergistic respiratory muscular system. This investigation was undertaken to examine the respiratory burst-generating mechanism and bilateral synchronization in the adult large lampery.

\section{METHODS}

Material and holding apparatus. Large adult arctic lamperys, Entosphenus
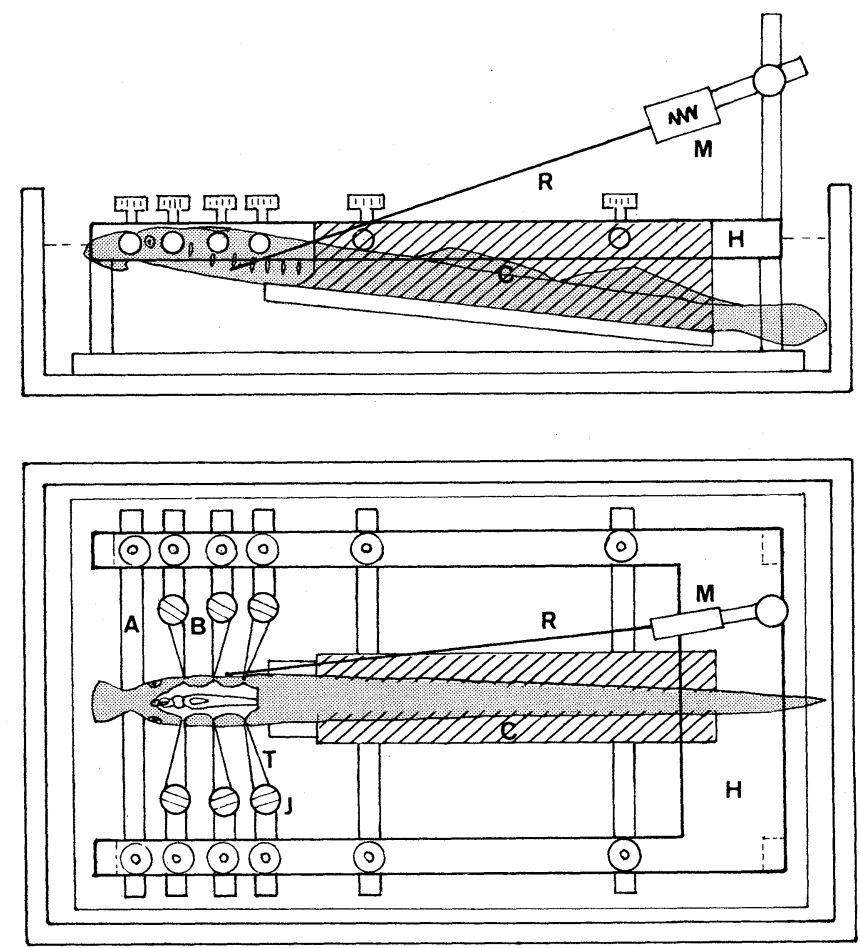

Fig. 1. Experimental arrangement (dorsal and lateral views). A, B and C: clamps for holding the lamprey. $\mathrm{J}$ : adjustable clamp. T: tweezers. $\mathrm{M}$ : strain-gauge transducer. R: fine tubular rod, $0.5 \mathrm{~mm}$ in diameter, made of stainless steel. $\mathrm{H}$ : base for holding the clamps. For further details see text. 
japonicus, $40-50 \mathrm{~cm}$ in body length, were obtained from the Agano River and were kept in aerated fresh water at $4^{\circ} \mathrm{C}$. Animals were anesthetized in iced water with MS222 $(1: 10,000)$ and were then fixed in the holder (Fig. 1). The holder was fastened at the bottom of a lucite chamber with a capacity of $10 l$, which was constantly aerated throughout the experiments. The holder basically consists of three elements, a trunk clamp (C) and head clamps (A and B). Clamp A consists of a pair of rods ( $8 \mathrm{~mm}$ in diameter), in the ends of which are cut V-or U-shaped notches of a size that fits the buccal funnel of the animal. Clamp $B$ consists of tweezers ( $T$ in Fig. 1) and adjustable clamps ( $J$ in Fig. 1). Trunk clamp (C) is made of wood, and grooves are cut in the two halves to fit the trunk of the animal.

After the animal is held by clamps $\mathrm{A}$ and $\mathrm{C}$, the dorsal musculature was slit along the dorsal midline through the branchial region, and the brain and a part of the spinal cord were exposed. The slit dorsal musculature was pinched by tweezers ( $T$ ) and clamp $J$ was adjusted and then fastened. The brain was transected behind the medulla oblongata and the spinal cord was crushed by piercing with a wire.

After all clamping was completed, the branchial muscles on both sides were left free to contract. Respiratory branchial movement was observed to last for more than $7 \mathrm{hr}$ in many preparations.

Lesions of the brain. After removal of the choroid plexus surgical sections

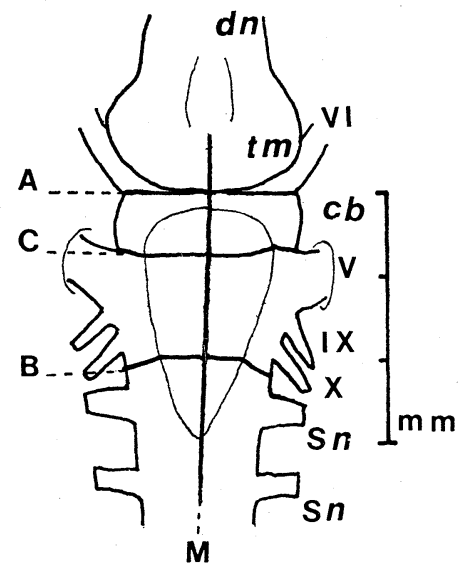

Fig. 2. Dorsal aspect of rhombencephalon after removal of the choroid plexus. Heavy lines indicate the sites of transverse (A, B and C) and mid-sagittal (M) sections. A: the level of the sulcus rhombencephalicus (isthmus rhombencephali). B: the level of obex, caudally to the entry of the vagal rootlets. C: cranially to the entry of the Vth and VIIth nerves. cb, cerebellum; dn, diencephalon: tm, tectum mesencephalon; V-X, Vth-Xth cranial nerves; sn, spinal nerve. The medullary district delimited by $\mathrm{B}$ and $\mathrm{C}$ is referred to as the medial part of the medulla in the text. All of the cranial nerves remain intact. Scale: $3 \mathrm{~mm}$. 
were made through the brain-stem as indicated in Fig. 2. For this purpose segments of razor blades, with a $0.5-0.2 \mathrm{~mm}$ wide tip, were used. Due to being in a state of shock, the animals did not breathe spontaneously for some time after brain transection. During this period artificial ventilation was administered by pressing the branchial basket rhythmically with a finger. The ECG was monitored; it was a useful indicator during the shock period following transection. Additional technical details are given in the appropriate sections in RESULTS. All experiments were done at temperatures between 8 and $13^{\circ} \mathrm{C}$.

Neural activity was recorded by using a steel micro electrode $(1-5 \mu \mathrm{m}$ tip diameter) wich was insulated except for its tip. Signals were led to a cathode follower and DC amplifier, and were displayed on CRO for photographic recording. Respiratory movements were recorded isotonically using a strain-gauge transducer driven by one side of the branchial muscles. In order to decrease the burden on the muscles, the movements were conducted to a stainless steel tube $10 \mathrm{~mm}$ in length and $2 \mathrm{~mm}$ in diameter attached lightly to the branchial wall.

\section{RESULTS}

\section{The effects of transverse section in the brain-stem}

Transections were made to determine the site of the basic respiratory rhythmgenerator in the brain-stem. Figure 2 shows the brain from the dorsal aspect and illustrates the transection levels by heavy lines (A, B and C in Fig. 2). Transection was always followed by transient disorders in the respiratory pattern and a considerable decrease in heart rate which were observed for some time. However, sooner or later after this shock period, branchial movement was usually recovered and continued with the regular respiratory or periodic rhythm (see Fig. 3, control, initial effect and recovery). Therefore, transections, as indicated by $\mathrm{A}$ and $\mathrm{B}$ in Fig. 2, respectively, were not considered to affect substantially the respiratory rhythm-generator. It was noted that transection $B$ resulted in a considerable decrease in heart rate, in comparison with transections $\mathrm{A}$ and C (Fig. 3B).

When the transverse section was made at the level indicated by $\mathrm{C}$ in Fig. 2, respiratory movement invariably ceased abruptly (C in Fig. 3). However, 10-20 min after the section branchial movement was recovered and continued, although at a slower frequency (D, in Fig. 3). Even after the rostral and caudal parts of the medulla were removed by section, branchial movement continued regularly for more than $4 \mathrm{hr}$. Howevre, when the section was made at a level extending caudally further than $\mathrm{C}$ or cranially further than $\mathrm{B}$, the pattern of branchial movements became remarkably irregular or ceased altogether, and in most cases the change was irreversible even after $1 \mathrm{hr}$ or more. 




Fig. 3. The effect of transection of the brain-stem on respiratory movement. Upper trace, movement of branchial basket (contraction downwards). Lower trace, ECG. Arrows indicate the time of transection. A: control and the initial effect of transection A. B: recovery from transection A and the initial effect of transection B. Note decrease in heart rate. C: recovery from transection B and the initial effect of trancsetion $\mathrm{C}$. $\mathrm{D}$ : continuation from $\mathrm{C}$; $10 \mathrm{~min}, 15 \mathrm{~min}, 20 \mathrm{~min}$ and $35 \mathrm{~min}$, after transection $\mathrm{C}$, repeatedly.

\section{Neural activities in the medial part of the medulla}

After the brain was transected as indicated by B and C in Fig. 2, a microelectrode was inserted dorsoventrally into the medial part of the medulla. At depths of 1.5-2.0 mm, electrical activities were detected, correlating to the movement of the branchial basket. As shown in Fig. 4, these neural activities were apparently composed of spikes and slow sustained-potential, which lasted for about $0.1 \mathrm{sec}$. It was recognized that when the site of the electrode tip was changed, the amplitude of the spikes as well as the slow components changed independently. In Fig. 4C, the spikes are notable, while the slow potentials are marked 


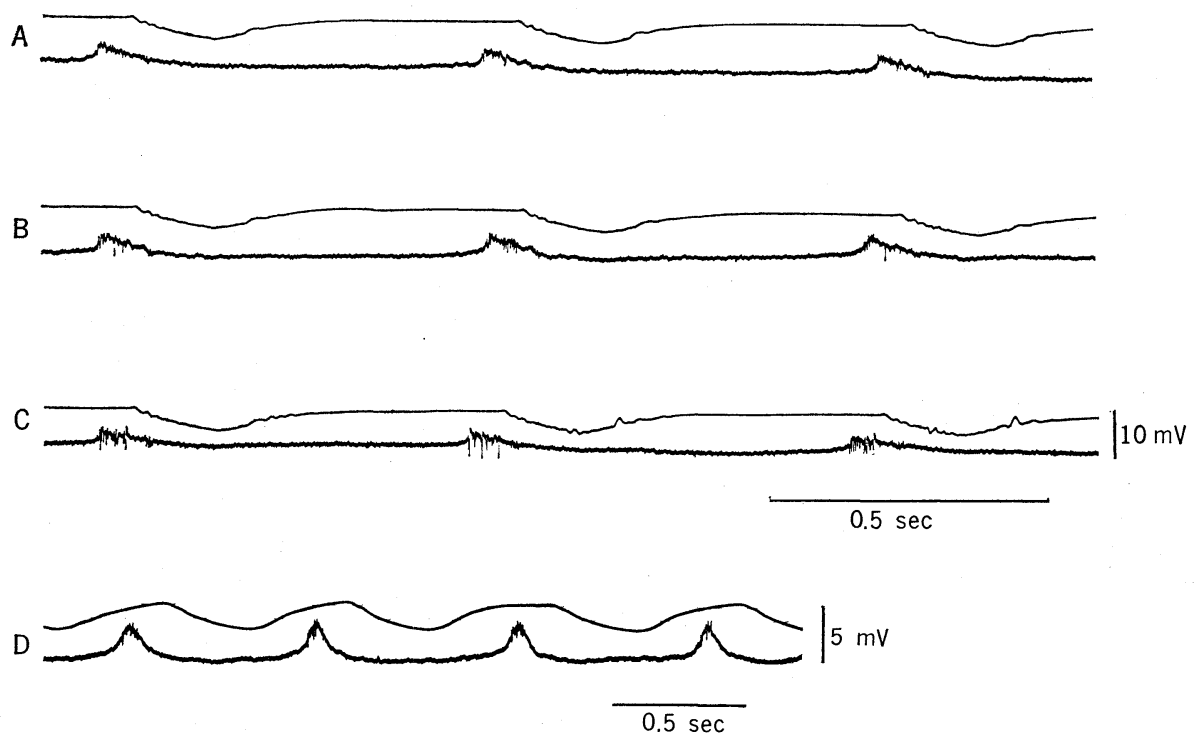

Fig. 4. Types of electrical activities in the isolated medial part of the medulla (as shown in Fig. 2), recorded simultaneously with branchial movement. Upper trace, branchial contraction (contraction downwards). Lower trace, electrical activities. A: the "spike-deficient" type. B: the intermediate type. C: the spike-definitive type. D: the "cardiac-pacemaker" type. Note the markedly slow potential during the resting phases in $B$ and $D$.

in Fig. 4B and 4D. We recorded the same type of discharges as those shown in Fig. 4C 13 times in the same individual, scattered throughout the medial part of the medulla, although a systematic search for the precise location and distribution of these neural recordings was not made. However that may be, all neural activities detected in the present experiment were related exclusively to only one phase of the respiratory cycle: branchial contraction. The respiratory discharges shown in Fig. 4 preceded the branchial contraction by about $0.1(0.06-$ 0.12 ) sec. Conduction velocities in motor axons in lampreys have been estimated to be about $1 \mathrm{~m} / \mathrm{sec}$ (RovaInen, 1974). Accordingly, the conduction time in the present experiments approximately corresponds to the distance between the medulla and the branchial muscles.

In the present experiment, a slow depolarization shift was successfully, detected, which precedes the onset of respiratory burst discharge. As is clearly shown in Fig. 4B and 4D, the potential shift is developing during the resting period of the respiratory discharges. Accordingly, this potential may be comparable with the so-called "diastolic slow depolarization." It could be suggested that the periodic burst discharges may be subserved or triggered by such a depolarization. As Fig. 4 shows, the slope of the potential shift was somewhat different according to the depth and site of the elecrode tip, suggesting that 
slow potential generators presumably are not located in a very confined area in the medulla. However, since the recordings were made extracellularly, the nature of their potential could not be analyzed in detail. when using intracelluar electrodes, it is necessary to test whether the slow potential generators are moto-

A
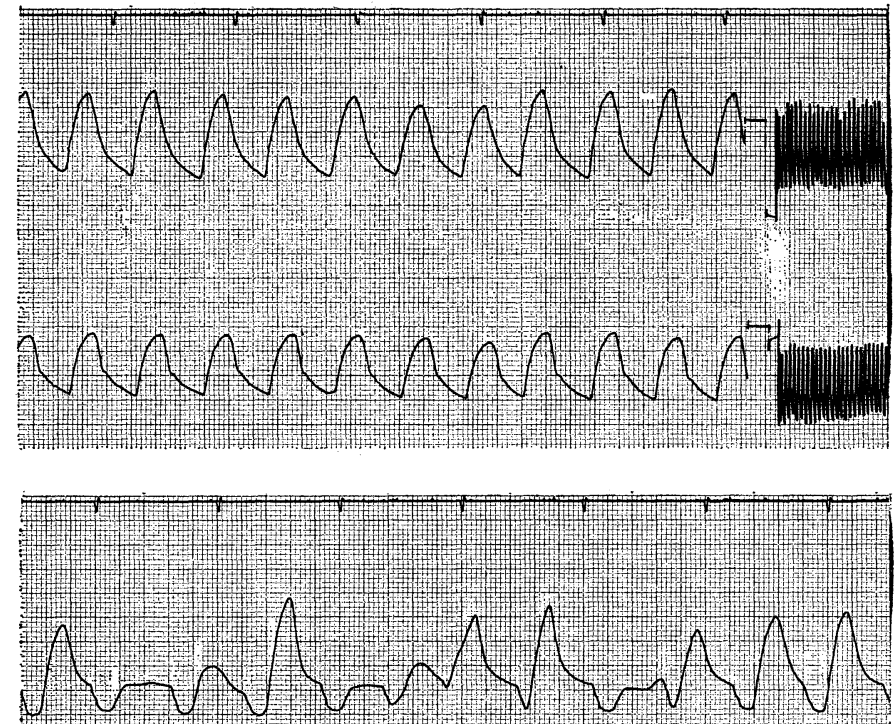

B
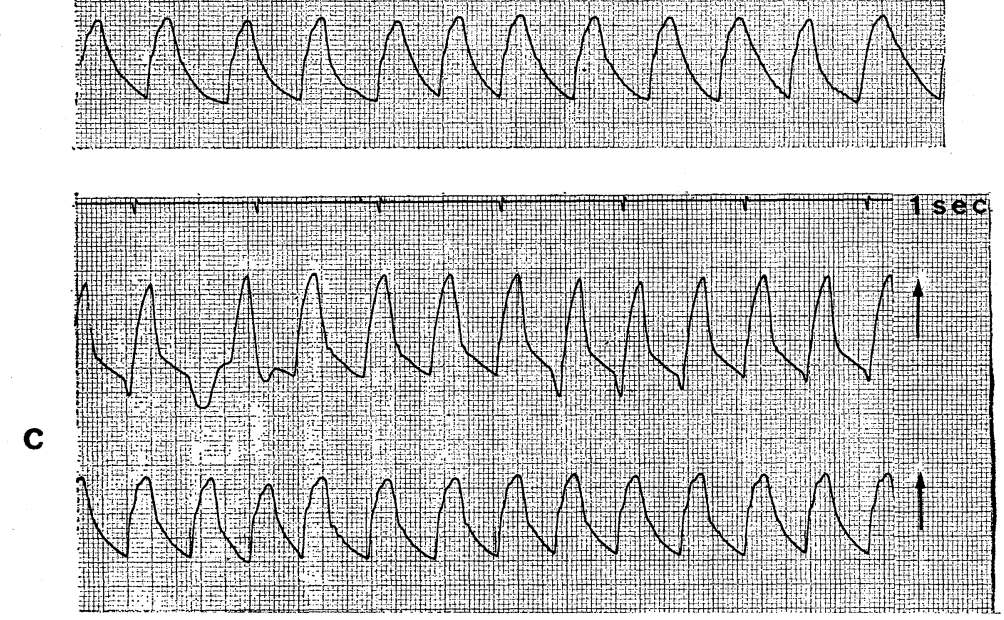

Fig. 5. Effects of midline section of the brain-stem on respiratory movement. Simultaneous recordings (upper trace, one side; lower trace, the other side) of lateral branchial movement. A: control, showing bilateral synchronization. $\mathrm{B}$ and $\mathrm{C}: 5 \mathrm{~min}$ and $10 \mathrm{~min}$ after the midline section, respectively. Arrow indicates branchial contraction upwards. 
neurons or not, and to determine the primary site of initiation of respiratory burst discharges in the medulla.

\section{Effect of midline brain-stem sectioning}

Division of the brain-stem into the left and right halves was done by means of a sagittal section along the midline as indicated by heavy line $\mathrm{M}$ in Fig. 2 . After sectioning there were always transient disorders in the branchial movements. After such an initial shock period, branchial movements were observed in many cases on both sides, while bilateral synchronization was completely disturbed; the two rhythms were independent (Fig. 5B, C). One side continued normal movements (Fig. 5B, lower trace), while the other side had a lesser frequency (Fig. 5B, upper trace). However, the latter increased in rate gradually during the course of the experiments after sectioning (Fig. 5C, upper trace).

As shown in Fig. 6, both halves showed independently periodic discharges followed by branchial movements; the right half decreased in frequency (Fig. 6C), while the left half (Fig. 6A) showed an original respiratory rhythm. Figure $6 \mathrm{~B}$ shows simultaneous recordings of discharges in the right half of the brain and branchial movements in the left side of the body. In only a few cases after midline sectioning was branchial contraction observed ipsilaterally.

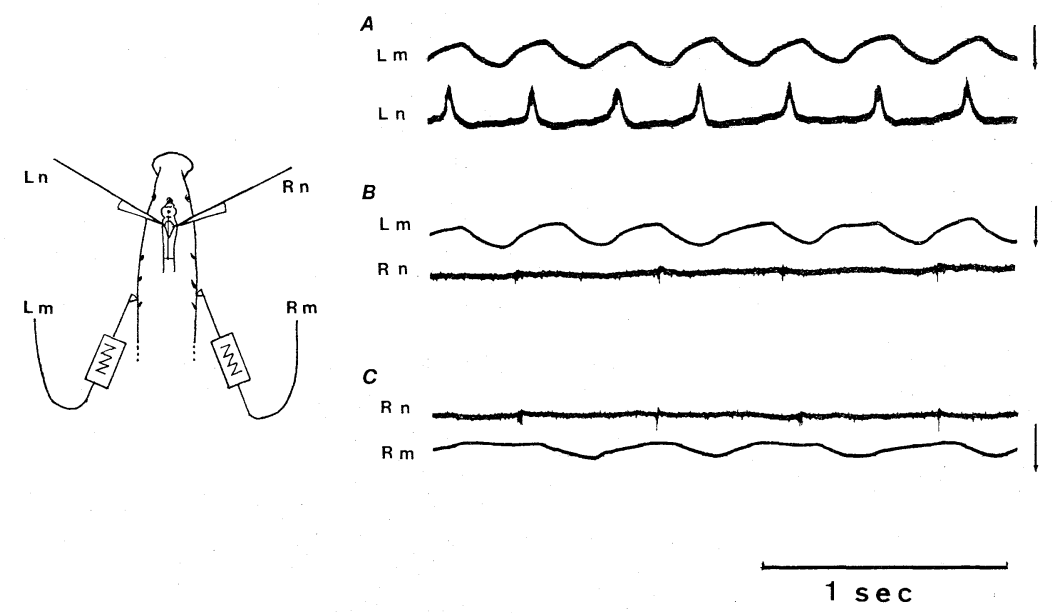

Fig. 6. Effects of midline section of the brain-stem on neural activities in the medulla and on branchial movement. Lm, Rm: respiratory movement of left and right sides (contraction downwards). Ln, Rn: medullary discharges in the left and right halves of the brain-stem.

\section{DISCUSSION}

1. Lesion of the medulla. This present experiment was performed using the whole body of a large adult lamprey fixed by a specially-designed holding 
apparatus. By sectioning the medulla transversally, it was found that the rostral and caudal parts of the medulla can be removed, without impairing its ability to produce respiratory rhythm; the medullary respiratory rhythm-generator was located in the remaining medial part between the two cross-section lines (indicated by $\mathrm{B}$ and $\mathrm{C}$ in Fig. 2).

According to histological examination of the brain-stem of Lamptera (NIEUWENHUYS, 1972), this part may be regarded as corresponding to the zone which includes the motor nucleus of the glossopharyngeal nerve and the rostral motor nucleus of the vagus. Motor innervation of branchial muscles is provided by the vagus and the glossopharyngeal nerve. Rovainen (1974) demonstrated that most of the motoneurons are located in those nuclei. It is likely that the basic medullary pattern of respiratory rhythm (medullary respiratory rhythm) may be generated near and/or within these nuclei.

RovAINEN (1974) revealed, using isolated brain-gill preparations from small adult lamprey, that removing the mid- and fore-brain by sectioning the isthmic region had no effect on respiration. In the case of larval lamprey, after transecting the brain-stem behind the Vth motor nucleus, branchial movement ceased, while periodic velar movements were not disturbed (HonMA, 1975). In the present experiment it was observed that after the rostral part of the medulla was removed, respiratory movements slowed in frequency. Accordingly, the possibility cannot be excluded that in the adult lamprey pontine districts (rostral medulla in Fig. 2) subserve the generation of 'normal' respiratory rhythm.

2. Slow potential preceding respiratory burst activities. ROVAINEN (1974) has shown periodic EPSP bursts recorded from branchial motoneurons in the brainstem of the adult lamprey. However, the origin of the periodic excitatory input to the motoneurons has not been identified. In the present experiment external recordings detected slow potential change, which progressively increased during the resting period of respiratory burst discharges and was finally followed by discharge and branchial contraction. This potential, the so-called diastolic slow potential, sounds very much like those seen in pacemaking and periodic burst cells or in the specialized muscles of the mammlian heart. Neural activities detected in the present experiment are apparently similar in shape to those generated in the crustacean heart ganglion (MATSUI, 1955; MAYNARD, 1955; HAGIWARA and Bullock, 1957).

In the crustacean (Squilla) heart ganglion, the slow potential is regarded as being produced in somata or dendrites in the pacemaker neurons and initiates periodic trains of spikes in axons (WATANABE et al., 1967a). According to WATANABE et al. (1967b), the slow potentials are not synaptic potentials and resemble in several characteristics those found in the mammalian heart pacemaker (Trautwein and Kassebaum, 1961).

ADRIAN and BUYTENDIJK (1931) observed a slow rhythmical potential change in isolated goldfish brain and advanced the hypothesis that the recorded slow 
potential is due to gradual depolarization and recovery of the nerve cells, and that depolarization triggers rhythmic burst discharges in the respiratory motor axons. Apparently, it is necessary to reevaluate their hypothesis for consideration of the mechainism of respiratory rhythm generation in general.

3. In comparison with the neurogenic heart. In this experiment all the medullary periodic discharges detected were correlated exclusively to only one phase of the respiratory cycle: branchial contraction. Although a systematic search for topographical information on the location of recorded activities in the same animal is necessary, it is unlikely that the medial part of the medulla includes such (inhibitory) neurons, which act as members of a reciprocal inhibition network.

As is well known, in members of the gnathostomata, medullary respiratory neurons can basically be divided into two, or at most three, groups, corresponding to the synergist and/or the antagonist in the respiratory muscular system, respectively (Hukuhara and OKada, 1956; Hughes and Shelton, 1962; Baumgarten and Salmoiraghi, 1962; Hughes, 1963; Ballintiun, 1969; Waldron, 1972). On the other hand, the adult lamprey possesses only the synergist (branchial constrictor muscle) in its respiratory apparatus (ROBERTS, 1950; RANDALL, 1972). Generally, in the case of the higher crustacen heart (neurogenic heart) all the neurons in the ganglion fire and correspond to only one phase of the cycle: cardiac contraction (MAYNARD, 1955; MATSUI, 1955; Hagiwara and Bullock, 1957; Prosser, 1965). Accordingly, the relationship of the respiratory center and the muscular system in the adult lamprey may be comparable to that of the pacemaker ganglions and the cardiac muscle in the neurogenic heart.

In the crustacean heart ganglion, the cell somata are connected with each other via denrodendritic electrotonic connections, so that the slow potential spreads from one cell to another and synchronization of the slow potnetial among neurons is achieved (WATANABE et al., 1967a). In the lampery also the possibility must be considered that the diastolic slow potential detected externally in the present experiment could be a sort of synchronized potential, which is achieved by electrotonic connections of the possible respiratory pacemaker (neurons).

4. Bilateral synchronization. It is known that normal respiratory movements in lampery are bilateral and synchronous (ROBERTS, 1950), and the bilateral pathways are interrupted by slitting the midline of the rostral medulla (RovAINEN, 1974). In the present experiment complete division of the brain-stem into two halves by a midline section revealed that each of the halves possesses, respectively its own central respiratory activity; one half continued at the same frequency, while the other half functioned with a slower rhythm than the former. It may be a reasonable explanation that under normal conditions one half functions as a respiratory pacemaker and the other half behaves as a follower. Bilateral synchronization may be achieved by the former dominating the latter by bilateral 
connections which mediate with each other. The latter (the follower) may be able to take over true pacemaker function when the former (the pacemaker) is depressed in frequency or when the bilateral pathway is interrupted by midline sectioning.

Presumably in the lamprey, it is not unlikely that respiratory pacemaker neurons are not located in an extremely confined area but are diffusely and bilaterally distributed, connectiong with each other electrically. However, the key investigation to demonstrate this assumption is to show by intracellular recording that the diastolic slow depolarization is not due to excitatory synaptic input from another site in the medulla but endogenously generated in the pacemaker itself.

\section{REFERENCES}

Addens, J. L. (1933) The motor nuclei and roots of the cranial and first spinal nerves of vertebrates. Z. Ges. Anat., 1. Abt., 101: 307-410.

Adrian, E. D. and BuytendiJK, F. J. J. (1931) Potential changes in the isolated brain stem of the goldfish. J. Physiol. (Lond.), 71: 121-135.

Ballintisn, C. M. (1969) Functional anatomy and movement co-ordination of the respiratory pump of the carp (Cyprinus carpio L.). J. Exp. Biol., 50: 547-567.

Baumgarten, R. V. and Salmoiraghi, G.C. (1962) Respiratory neurones in the goldfish. Arch. Ital. Biol., 100: 31-47.

CoRds, E. (1929) Die Kopfnerven der Petromyzonten. Z. Anat. Entwicklungsgesch., 89: 201249.

Hagiwara, S. and Bullock, T. H. (1957) Intracellular potentials in pacemaker and integrative neurons of the lobster cardiac ganglion. J. Cell. Comp. Physiol., 50; 25-47.

HeAley, E. G. (1972) The central nervous system. In: The Biology of Lampreys, Vol. 2, ed. by Hardisty, M. W. and Potter, I. C., Academic Press, London, pp. 307-372.

Honma, S. (1975) Velar motoneurons of lamprey larvae. J. Comp. Physiol., 104: 175-183.

Hukuhara, T. and OKadA, H. (1956) On the automaticity of the respiratory centers of the catfish and crucian carp. Jpn. J. Physiol., 6: 313-320.

Hughes, G. M. (1963) Vertebrate Respiration, ed. by Hughes, G. M. Heinemann Educational Books, London, pp. 79-83.

Hughes, C. M. and Shelton, G. (1962) Respiratory Mechanisms and Their Nervous Control in Fish, Advances in Comparative Physiology and Biochemistry, Vol. 1, Academic Press. pp. 275-361.

KAWASAKI, R. (1978) The diastolic slow depolarization preceeding the medullary respiratory burst in the arctic lamprey. Zool. Mag., 87: 401 (abstr. in Japanese).

Lindstrom, T. (1949) On the cranial nerves of the cyclostomes with special reference to $\mathrm{n}$. trigeminus. Acta Zool. (Stockholm), 30: 315-458.

Matsui, K. (1955) Spontaneous discharges of the isolated ganglionic trunk of the lobster heart (Panulirus japoicus). Sci. Rep. Tokyo Kyoiku Daigaku, Sect. B., 7: 257-268.

MAYNARD, D. M. (1955) Activity in a crustacean ganglion. II. Pattern and interaction in burst formation. Biol. Bull., 109: 420-436.

Nieuwenhuys, R. (1972) Topological analysis of the brain stem of the lamprey Lampetra fluviatilis. J. Comp. Neurol., 145: 165-178.

Prosser, C. L. (1965) Pacemakers. In: Comparative Animal Physiology, 2nd ed, ed. by Prosser, C. I. and Brown, F. A., Jr. Saunders, Philadelphia, pp. 396-402.

Randall, D. J. (1972) Respiration. In: The Biology of Lampreys, Vol. 2, ed. by Hardisty, 
M. W. and Potter, I. C., Academic Press, London, pp. 287-306.

Roberts, T. D. M. (1950) The respiratory movements of the lamprey (Lampetra fluviatilis). Proc. R. Soc. Edinb. (Biol.), 64: 235-252.

Rovainen, C. M. (1974) Respiratory motoneurons in lampreys. J. Comp. Phyiol., 94: 57-68.

Rovainen, C. M. (1977) Neural control of ventilation in the lamprey. Fed. Proc., 36: 2386-2389.

Trautwein, W. and Kassebaum, D. G. (1961) On the mechnism of spontaneous impulse generation in the pacemaker of the heart. J. Gen. Physiol., 45: 317-330.

TretjakofF, D. (1927) Das periphere Nervensystem des Flussneunauges. Z. Wiss. Zool. Abt. A, 129: 359-452.

Watanabe, A., Obara, S., Akiyama, T., and Yumoto, K. (1967a) Electrical properties of the pacemaker neurons in the heart ganglion of a stomatopod, Squilla oratoria. J. Gen. Physiol., 50: 813-838.

Watanabe, A., Obara, S., and Akiyama, T. (1967b) Pacemaker potentials for the periodic burst discharge in the heart of ganglion of a stomatopod, Squilla oratoria. J. Gen. Physiol., 50: 839-862.

WALDRON, I. (1972) Spacial organization of respiratory neurons in the medulla of tench and goldfish. J. Exp. Biol., 57: 449-459.

WyMAN, R. J. (1976) Neurophysiology of the motor outout pattern generator for breathing. Fed. Proc., 35: 2013-2023. 